\title{
Effect of Ca-substitution on the Magnetic and Dielectric Properties of Mn-Zn Ferrites
}

\author{
M. M. Rahman ${ }^{1 *}$, P. K. Halder ${ }^{1}$, F. Ahmed ${ }^{1}$, T. Hossain ${ }^{2}$, and M. Rahaman ${ }^{2}$ \\ ${ }^{1}$ Department of Physics, Jahangirnagar University, Savar, Dhaka-1342, Bangladesh \\ ${ }^{2}$ Institute of Fuel Research and Development (IFRD), Bangladesh Council of Scientific and \\ Industrial Research (BCSIR), Dhaka-1000, Bangladesh
}

Received 7 February 2012, accepted in final revised form 31 March 2012

\begin{abstract}
Spinel Mn-Zn ferrites with composition $\mathrm{Mn}_{\mathrm{x}} \mathrm{Zn}_{0.4} \mathrm{Ca}_{0.6-2 \mathrm{x}} \mathrm{Fe}_{2+\mathrm{x}} \mathrm{O}_{4}$, where $x=0.10,0.15$, $0.20,0.25$ and 0.30 have been prepared by conventional ceramic technique sintered at $1300{ }^{\circ} \mathrm{C}$ for 4 hours. The influence of Ca-substitution on various properties of $\mathrm{Mn}-\mathrm{Zn}$ ferrites have been studied in this work. Investigations were carried out by the measurements of Curie temperature, permeability, loss tangent, Q-factor, dielectric constant and AC resistivity of the samples. Curie temperature $\left(T_{c}\right)$, the real part of initial permeability $\left(\mu^{\prime}\right)$, loss tangent $(\tan \delta$ ), and AC resistivity have been found to be decreased while the $Q$-factor increases with the increase in Ca-content. The frequency characteristics of the dielectric constant and AC resistivity have been found to be decreased as the frequency increases. Maxwell-Wagner interfacial type of dielectric polarization was observed with the addition of Ca-content over the entire range of frequency considered.
\end{abstract}

Keywords: Spinel ferrites; Sintering temperature; Initial permeability; Dielectric constant.

(C) 2012 JSR Publications. ISSN: 2070-0237 (Print); 2070-0245 (Online). All rights reserved. doi: http://dx.doi.org/10.3329/jsr.v4i2.9752 J. Sci. Res. 4 (2), 297-306 (2012)

\section{Introduction}

Ferrites constitute a special class of magnetic oxide materials with general formula MO. $\mathrm{Fe}_{2} \mathrm{O}_{3}$, where $\mathrm{M}$ is a divalent metal ion such as $\mathrm{Mn}^{2+}, \mathrm{Zn}^{2+}, \mathrm{Ni}^{2+}, \mathrm{Cu}^{2+}, \mathrm{Mg}^{2+}, \mathrm{Co}^{2+}$ or $\mathrm{Cd}^{2+}$. These materials show semiconducting characteristics which are of great technological applications since they have high electrical resistivity as well as better magnetic qualities [1]. Among the soft magnetic materials for high frequency power electronics Mn-Zn ferrites is one of the most popular and smart candidate of highest rank [2]. These types of polycrystalline spinel ferrites have a wide variety of applications such as power electronics, ferrofluid technology, magnetic data storage, in transformers, choke

*Corresponding author: mahbub235@yahoo.com 
coils, noise filters and as contrast agents in magnetic resonance imaging [3-5]. It is well established that in Mn-Zn ferrites most of the $\mathrm{Zn}^{2+}$ ions occupy in tetrahedral A sites [6] which results in a lowering of $\mathrm{Fe}^{3+}$ in octahedral A-sites. Moreover, structural and other properties of ferrites are dependent on the quality of new materials, milling technique, preparation temperature, concentration of the dopants and impurities [7]. For these reasons, it is possible to introduce various metallic ions to these ferrites to improve their electronic and magnetic properties significantly [8]. In the last couple of decades a very large number of researches have realized in order to synthesize, to study the properties and to observe the effect of various additives on their properties [9-32]. Additives play an important role to modify the microstructure and properties of Mn-Zn ferrites generally by three basic mechanisms as mentioned in Ref. [25]. In refs. [26-27] it has been mentioned that $\mathrm{Co}^{3+}, \mathrm{Gd}^{3+}$ and $\mathrm{Eu}^{3+}$ ions replace the metallic cations in tetrahedral A-sites or octahedral B-sites to improve various properties of the samples. Effect of additions of $\mathrm{TiO}_{2}$, vanadium and tungsten on $\mathrm{Mn}-\mathrm{Zn}$ ferrites have been reported in refs. [29-31]. Addition of $\mathrm{CaO}$ in pure $\mathrm{Mn}-\mathrm{Zn}$ ferrites has been found to reduce the total power loss [32]. However, up until now, as far as we are concerned systematic study about the effect of Ca-substitution on the magnetic and dielectric properties of Mn-Zn ferrites are not available in the literature. For this reason, in this paper we report some systematic investigation on composition, temperature and frequency dependent magnetic, dielectric and electrical properties of Mn-Zn ferrites with the addition of Ca.

\section{Experimental Details}

Now-a-days different synthesis techniques are used with various dopants to produce polycrystalline spinel ferrites with enhanced structural, electromagnetic and dielectric properties suitable for magnetic, high-density magneto-optical recording media and microwave applications [33-34]. In the present work, conventional double sintering technology was used for the production of $\mathrm{Mn}-\mathrm{Zn}$ ferrites with $\mathrm{Ca}$ as a dopant for its simplicity and availability. The preparation and sintering facility available in the laboratory of Institutes of Fuel Research and Development (IFRD), Bangladesh Council of Scientific and Industrial Research (BCSIR), Dhaka-1000, Bangladesh has been used for this purpose. The raw materials $\mathrm{Fe}_{2} \mathrm{O}_{3}, \mathrm{MnO}, \mathrm{ZnO}$ and $\mathrm{CaO}$ were used as starting materials. The analytical research grade oxides as supplied by the manufacture E. Mark of Germany were used for the sample preparation process. Appropriate amount of raw metal oxides were mixed, crushed, grinded and milled. Milling was carried out in a wet medium to increase the degree of mixing. To avoid iron contamination, stainless steel balls were used in a steel ball milling machine and a fluid such as acetone is used to convert the mixture into slurry. The ground powders were presintered in air or oxygen at $600{ }^{0} \mathrm{C}$. Later on, the presintered powders were again crushed into the fine powders. Using diepunch assembly different shapes of dies were used to produce the finished products. Using the hydraulic press made of nonmagnetic stainless steel, we have prepared two types of samples: cylindrical and toroidal. The finished products were sintered at constant 
temperature of $1300{ }^{\circ} \mathrm{C}$ in air for four hours. A heating and cooling rate of $5{ }^{\circ} \mathrm{C} / \mathrm{min}$ was maintained throughout the sintering process.

\section{Results and Discussion}

Characterization and phase identification of the Mn-Zn samples were performed by X-ray diffraction (XRD) technique. A Philips X'Pert Pro X-ray diffractometer has been used for this purpose using $\mathrm{Cu}-\mathrm{K}_{\alpha}$ radiation. XRD pattern of $\mathrm{Mn}_{\mathrm{x}} \mathrm{Zn}_{0.4} \mathrm{Ca}_{0.6-2 \mathrm{x}} \mathrm{Fe}_{2+\mathrm{x}} \mathrm{O}_{4}$, where $x=$ $0.00,0.10,0.20$ and 0.30 has been presented in Fig. 1. XRD patterns confirmed the singlephase cubic spinel structure of the samples without having any other intermediate phases. All the samples have been found to show crystallization, with well-defined diffraction lines. According to the XRD data various diffraction peaks appeared at different planes (111), (220), (311), (222), (400), (422), (511), and (440). It is observed that all the diffraction peaks are either all odd or all even which indicates the samples are spinel in phase. Generally, for the spinel ferrites the peak intensity depends on the concentration of magnetic ions in the lattice. The intensity of the samples has been found to be reduced as the amount of Ca-content is increased.

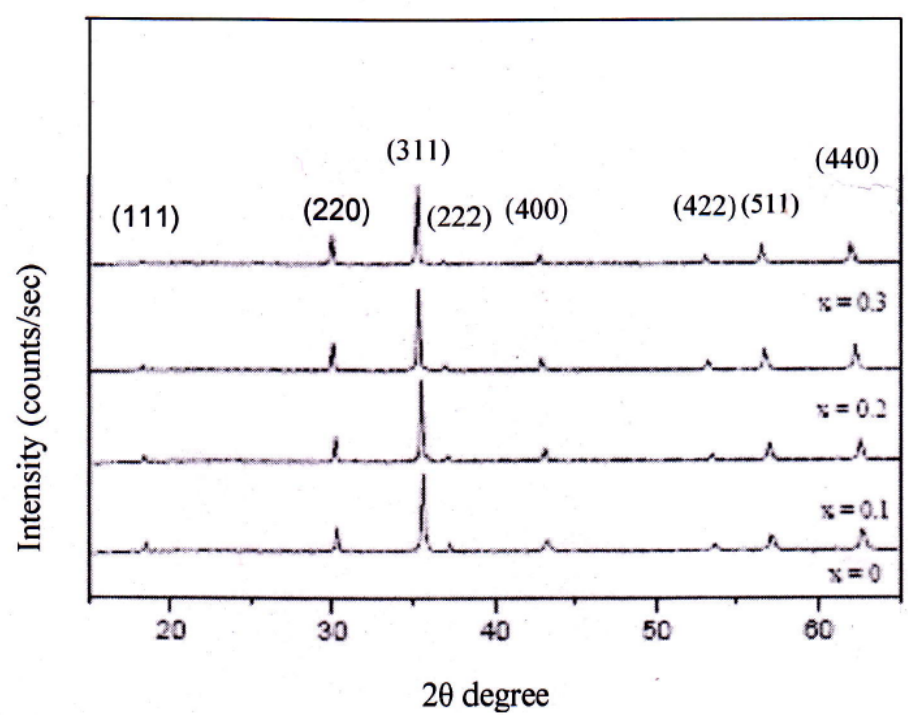

Fig. 1. X-ray diffraction (XRD) pattern of $\mathrm{Mn}_{\mathrm{x}} \mathrm{Zn}_{0.4} \mathrm{Ca}_{0.6-2 \mathrm{x}} \mathrm{Fe}_{2+\mathrm{x}} \mathrm{O}_{4}$, where $x=0.00,0.10,0.20$ and 0.30 .

Curie temperature, $T_{c}$ corresponds to the temperature at which a magnetically ordered material becomes magnetically disordered, i.e., a ferromagnetic or a ferrimagnetic material becomes paramagnetic one. $T_{c}$ of $\mathrm{Mn}-\mathrm{Zn}$ ferrite samples were determined from 
the temperature dependence of initial permeability curves. According to Fig. 2, it is observed that $T_{c}$ decreases with the increase of Ca-content. $T_{c}$ values of Ca-substituted Mn-Zn ferrites have been presented in Table 1. A. Gonchar [35] also reported the similar results. This decrease of $T_{c}$ with Ca-substitution may be attributed to the fact of the weakening of exchange interaction according to Neel's model. Another earlier study with Cu-substituted cadmium-chromium ferrites [16] also gives support of our findings. It is well known fact that the magnetic characteristics of Mn-Zn ferrites are controlled by the Fe-Fe interaction. Addition of suitable dopant can replace the iron cations which in turn causing the alternation of magnetic behavior of the samples. In ferrites, there are three kinds of interactions between the tetrahedral A-sites and octahedral B-sites: A-A interaction, B-B interaction and A-B interaction [36]. Among these three types of interactions A-B interaction is strongest [36]. Since B-sites have more iron ions than Asites, addition of $\mathrm{Ca}$ ions enters into the A-sites. At the same time, few iron ions are moved into the B-sites, thereby reducing the strength of A-B exchange interaction and hence the $T_{c}$ decreases.

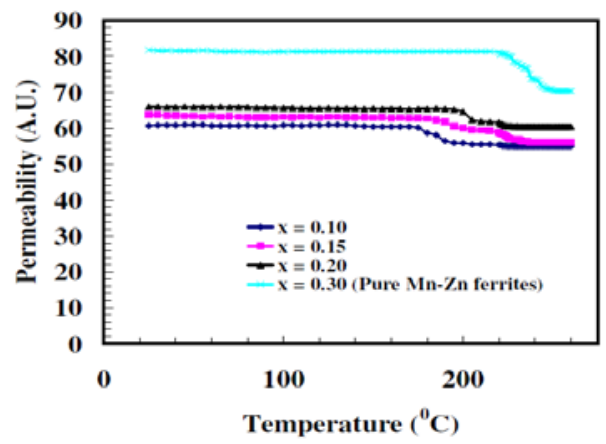

Fig. 2. Curie temperature of $\mathrm{Mn}_{\mathrm{x}} \mathrm{Zn}_{0.4} \mathrm{Ca}_{0.6-2 \mathrm{x}}$ $\mathrm{Fe}_{2+\mathrm{x}} \mathrm{O}_{4}$ where, $\mathrm{x}=0.10,0.15,0.20$ and 0.30 with temneratıre

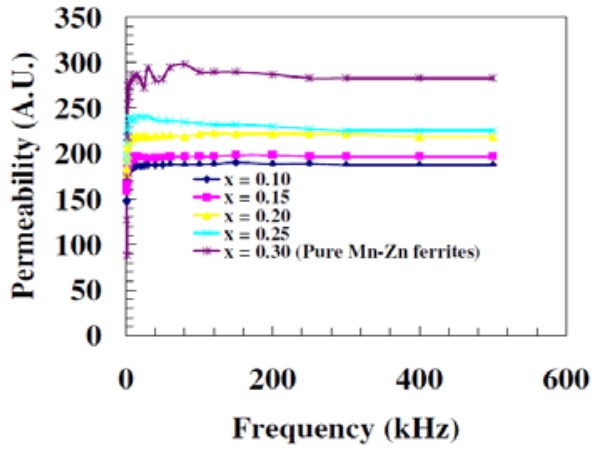

Fig. 3. Permeability versus frequency curves of $\mathrm{Mn}_{\mathrm{x}} \mathrm{Zn}_{0.4} \mathrm{Ca}_{0.6-2 \mathrm{x}} \mathrm{Fe}_{2+\mathrm{x}} \mathrm{O}_{4}$ where, $\mathrm{x}=0.10$, $0.15,0.20,0.25$ and 0.30 .

Table 1. Curie temperature of Mn-Zn ferrites with Ca-content.

\begin{tabular}{ccc}
\hline Composition & $x$ & Curie temperature, $T\left({ }^{\circ} \mathrm{C}\right)$ \\
\hline $\mathrm{Mn}_{\mathrm{x}} \mathrm{Zn}_{0.4} \mathrm{Ca}_{0.6-2 \mathrm{x}} \mathrm{Fe}_{2+\mathrm{x}} \mathrm{O}_{4}$ & 0.10 & 175 \\
& 0.15 & 185 \\
& 0.20 & 195 \\
& 0.30 & 220 \\
\hline
\end{tabular}


Permeability measures the degree of penetration of magnetic field through a magnetic substance. According to the permeability data presented in Fig. 3, it is observed that the real part of the initial permeability of Mn-Zn ferrites decreases with the addition of Ca. It may be stated that with a small addition of $\mathrm{Ca}$ on the Mn-Zn ferrites the density might have been decreased which lead to a decrease in permeability. Our result has been found to be in agreement with the previous investigations: ferrites with higher density and larger average grain size posses a high initial permeability and vice versa [37].

Permeability of polycrystalline ferrites is correlated with two types of mechanisms [38-39]. The mechanisms are: domain wall motion and the spin rotational magnetization inside the domains. As the $\mathrm{Ca}$ is added to $\mathrm{Mn}-\mathrm{Zn}$ ferrites calcium iron oxide generates and segregate at the grain boundaries pining at the domain wall. For this reason, domain wall energy is increased and the permeability is decreased [40]. The intragranular pores might also be responsible for the pining of the domain walls which results to deterioration of magnetic properties of Mn-Zn ferrites [25]. In our observation, it was also observed that over the entire frequency range the permeability remains almost constant. This might reflect the fact no structural relaxations or resonances are taking place in the observed frequency spectra.

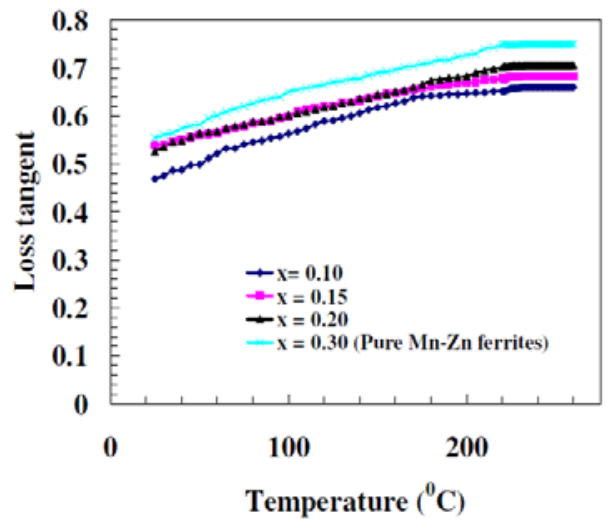

Fig. 4. Loss tangent of $\mathrm{Mn}_{\mathrm{x}} \mathrm{Zn}_{0.4} \mathrm{Ca}_{0.6-2 \mathrm{x}} \mathrm{Fe}_{2+\mathrm{x}} \mathrm{O}_{4}$ where $x=0.10,0.15,0.20$, and 0.30 as a function of temperature.

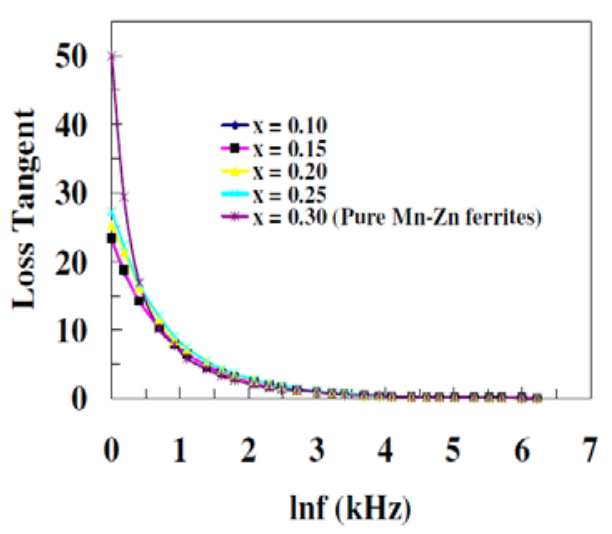

Fig. 5. Loss tangent of $\mathrm{Mn}_{\mathrm{x}} \mathrm{Zn}_{0.4} \mathrm{Ca}_{0.6-2 \mathrm{x}} \mathrm{Fe}_{2+\mathrm{x}} \mathrm{O}_{4}$ where $x=0.10,0.15,0.20,0.25$ and 0.30 as a function of frequency.

Figs. 4 and 5 show that the loss tangent of Mn-Zn ferrites with Ca addition as a function of temperature and frequency respectively. These measurements were performed in the temperature range of 25 to $275{ }^{\circ} \mathrm{C}$ and over the frequency range from $1 \mathrm{kHz}$ to 500 $\mathrm{kHz}$. According to the data, it is found that the loss tangent of Mn-Zn ferrites decreases gradually with the increase in Ca-content. At lower frequency side around $1 \mathrm{kHz}$, the loss factor is high but it starts decreasing with the increase in frequency and at high frequency it becomes almost unaffected with the frequency. In ferrites loss tangent, generally, arises 
due to non-uniform and non-repetitive domain wall motion, various domain defects, variations of flux density and annihilation of domain walls [41]. It is known that at high frequencies losses are to be lower if domain wall motion is inhibited and the magnetization is forced to change by rotation [42]. The decrease of loss tangent with the increase in frequency might attribute the relaxation phenomena of magnetization of domain walls [43]. Higher loss tangent at low frequency side may be due to the interfacial type of polarization [44].

The variations of Q-factor with temperature and frequency for the prepared $\mathrm{Mn}-\mathrm{Zn}$ ferrites without and with different amount of Ca-contents are shown in Figs. 6 and 7. From these two diagrams it is observed that the Q-factor of Mn-Zn ferrites increases with the increase in Ca-content which has been found to be consistent with our loss tangent measurements data. It is also observed that the Q-factor increases with the increase in frequency and resistivity. Generally, higher Q-values are due to the high resistivity of the samples [45]. Samples prepared by conventional double sintering method possess high losses with low Q-values [46]. In Ref. [46] it is also mentioned that at low frequency region materials with low Q-values work as better filters. These types of filters can be used to minimize undesirable oscillations and high frequency content of rapidly passing signals. These materials are successfully used to reduce ringing at high frequency applications.

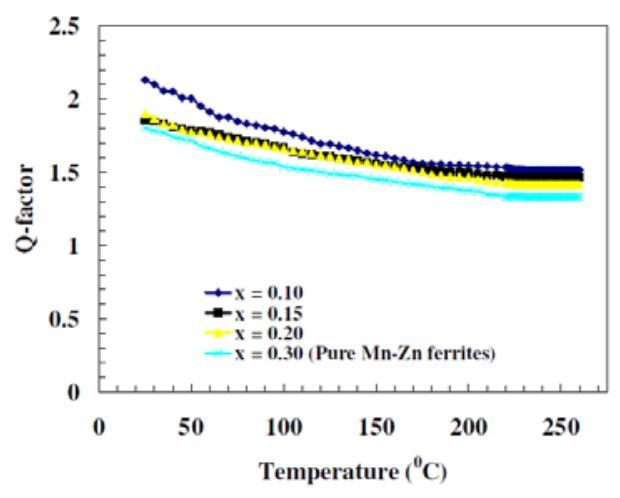

Fig. 6. Q-factor of $\mathrm{Mn}_{\mathrm{x}} \mathrm{Zn}_{0.4} \mathrm{Ca}_{0.6-2 \mathrm{x}} \mathrm{Fe}_{2+\mathrm{x}} \mathrm{O}_{4}$ where $\mathrm{x}=0.10,0.15,0.20,0.25$ and 0.30 as a function of temperature.

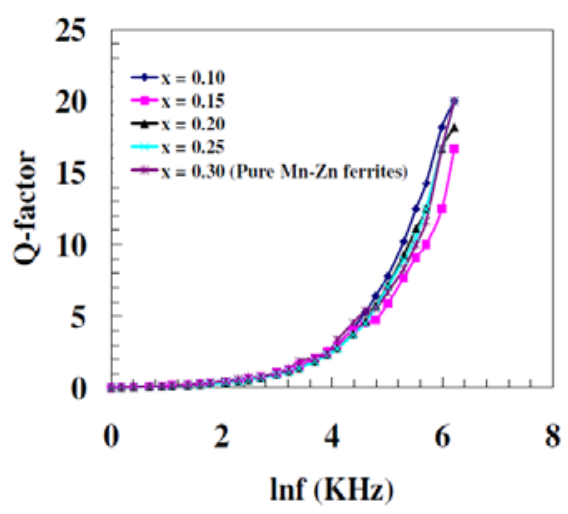

Fig. 7. Q-factor of $\mathrm{Mn}_{\mathrm{x}} \mathrm{Zn}_{0.4} \mathrm{Ca}_{0.6-2 \mathrm{x}} \mathrm{Fe}_{2+\mathrm{x}} \mathrm{O}_{4}$ where $\mathrm{x}=0.10,0.15,0.20,0.25$ and 0.30 as a function of freauencv.

Dielectric constant of Mn-Zn ferrites has been calculated by measuring capacitance using the formula:

$$
\epsilon^{-}=\frac{C d}{\epsilon A} \text {. }
$$

where $\epsilon^{\prime}$ is the dielectric constant, $C$ is the capacitance of the sample, $d$ is the thickness of the sample, $\epsilon$ is a constant and $A$ is the area of the circular sample $=\pi r^{2}$, where $\mathrm{r}$ is the 
radius of the sample. Fig. 8 shows the variation of dielectric constant with frequency from $1 \mathrm{kHz}$ to $500 \mathrm{kHz}$ at room temperature. The dielectric constant, $\varepsilon^{\prime}$ decreases with increasing frequency, which is rapid at lower frequencies and slower at higher frequencies. At much higher frequency it is very small and becomes independent of frequency. This is a normal dielectric behavior observed in most of the ferromagnetic materials, which may be due to the interfacial polarization as predicted by Maxwell and Wagner [43]. Similar types of dielectric dispersions are also reported in earlier [26, 4748]. A strong correlation between the dielectric constant and conduction mechanism are available in the literature [40]. Dielectric constant of ferrites depends upon the number of available $\mathrm{Fe}^{2+}$ ions on the $\mathrm{B}$-sites. The hopping of electrons between $\mathrm{Fe}^{2+}$ and $\mathrm{Fe}^{3+}$, and $\mathrm{Mn}^{2+}$ and $\mathrm{Mn}^{3+}$ causes local movements of electrons. Dielectric polarizations arise due to these local displacements of electrons which in turn gives raise the dielectric constant of ferrites [49]. Addition of Ca forms a non-magnetic calcium-iron-oxide which segregates at grain boundaries results in an increase of $\mathrm{Fe}^{2+}$ and decrease of $\mathrm{Mn}^{3+}$ inside the grains that lead to an increase in dielectric constant. It is also known that dielectric constant of ferrites are correlated to the different types of polarization mechanisms [50]. Space charge polarization becomes dominant at low frequencies [50]. Increase of frequency weakens the space charge polarization which in turn causes to decrease of dielectric constant. However, various types of defects and dislocations in the crystal lattice invite the interfacial polarization to be active in the low frequency region [51-53]. For this reason, dielectric constant is higher at low frequency side.

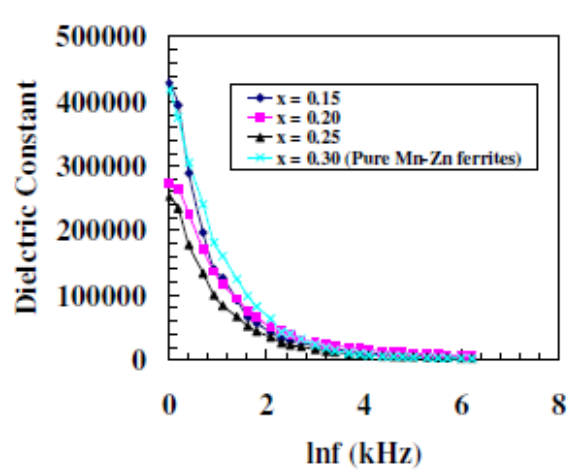

Fig. 8. Dielectric constant of $\mathrm{Mn}_{\mathrm{x}} \mathrm{Zn}_{0.4} \mathrm{Ca}_{0.6-2 \mathrm{x}} \mathrm{Fe}_{2+\mathrm{x}} \mathrm{O}_{4}$ where $x=0.10$, $0.15,0.20,0.25$ and 0.30 as a function of freauencv.

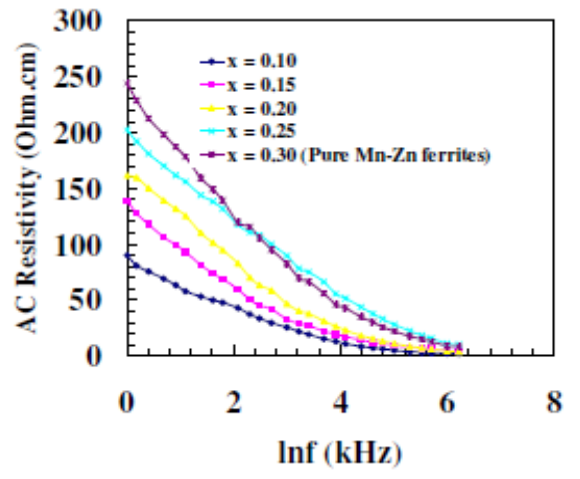

Fig. 9. AC resistivity of $\mathrm{Mn}_{\mathrm{x}} \mathrm{Zn}_{0.4} \mathrm{Ca}_{0.6-2 \mathrm{x}}$ $\mathrm{Fe}_{2+\mathrm{x}} \mathrm{O}_{4}$ where $x=0.10,0.15,0.20,0.25$ and 0.30 as a function of frequency.

Resistivity of ferrites depends upon the method of preparation, chemical composition, grain size and sintering conditions. Fig. 9 shows the variation of AC resistivity of Mn-Zn ferrites without and with Ca-addition as a function of frequency at room temperature. According to the resistivity data, it has been noticed that with the addition of Ca-content 
AC resistivity of Mn-Zn ferrites decreases. It has been also found that at lower frequency region the resistivity decreases faster comparing to the higher frequency region and at much higher frequency the resistivity of the Mn-Zn become almost independent of frequency. This means that all the samples show typical ferromagnetic behavior with frequency [54]. The conduction mechanism in ferrites is similar to the dielectric dispersion which is already discussed in the dielectric properties of ferrites of this paper. With the addition of Ca to the Mn-Zn ferrites the mobility of charge carriers is increased. The increased mobility results in an increase of conductivity and thereby resistivity is decreased. At high frequency region, the hopping frequency can no longer follow the frequency of the applied ac field and hence the resistivity becomes almost invariant [53]. During the moment when the jumping frequency of hopping charge carriers are equal to that of the applied field; resistivity becomes minimum and resonance takes place.

\section{Conclusions}

Curie temperature of $\mathrm{Mn}-\mathrm{Zn}$ ferrites decreases with increasing Ca-content due to the decrease of strength of exchange interaction. Frequency stability of the real part of permeability increases with increasing Ca-content. The loss tangent decreases with increasing frequency and with increase Ca-content. Since the Q-factor and loss tangent are reciprocal to each other, the Q-factor increases with the increase in frequency and with the addition of Ca-content. The frequency dependence of the dielectric constant of all the samples decreases with increasing frequency, which confirms the normal dielectric behavior of the samples. Initially, the resistivity decreases rapidly with increasing frequency. The increases frequency enhances the hopping frequency of the charge carriers between $\mathrm{Fe}^{2+}$ and $\mathrm{Fe}^{3+}$. As a result, both the dielectric constant and resistivity decreases. Throughout the study, it has been observed that the addition of Ca-content greatly influences the electro-magnetic and dielectric properties of the Mn-Zn ferrites.

\section{Acknowledgements}

The present study has been performed in the laboratories of Bangladesh Council of Scientific and Industrial Research (BCSIR) and Materials Science Division, Atomic Energy Centre Dhaka (AECD), Dhaka-1000, Bangladesh. Authors are also grateful to the Department of Physics, Jahangirnagar University, Savar, Dhaka-1342, Bangladesh.

\section{References}

1. A. Goldman, Modern Ferrite Technology (Marcel Dekker, Inc., New York, 1993).

2. M. Sugimoto, J. Am. Ceram. Soc. 82, 269 (1999). http://dx.doi.org/10.1111/j.1551-2916.1999.tb20058.x

3. V. Sepelăk, P. Heitjam, and K. D. Becker, J. Therm. Anal. Calorim. 90, 93 (2007). http://dx.doi.org/10.1007/s10973-007-8481-1

4. J. Nie, H. Li, Z. Feng, and H. He, J. Magn. Magn. Mater. 265, 172 (2003). http://dx.doi.org/10.1016/S0304-8853(03)00262-2 
5. Q. Yan, R. J. Gambio, S. Sampath, L. H. Lewis, L. Li, E. Baumberger, A. Vaidya, and H. Xiong, Acta Mater. 52, 3347 (2004). http://dx.doi.org/10.1016/j.actamat.2004.03.032

6. S. Modak, M. Ammar, F. Mazaleyrat, S. Das, and P. K. Chakrabarti, J. Alloys Compd. 473, 15 (2009). http://dx.doi.org/10.1016/j.jallcom.2008.06.020

7. J. Töpfer, H. Kahnt, P. Nauber, S. Senz, and D. Hesse, J. Euro. Ceram. Soc. 2, 3045 (2005).

8. H. Su, H. W. Zhang, X. L. Tang, and Y. Shi, J. Alloys Compd. 468, 290 (2009). http://dx.doi.org/10.1016/j.jallcom.2007.12.081

9. S. -F. Wang, Y. -R. Wang, T. C. K. Yang, P. -J. Wang, and C. -A. Lu, J. Magn. Magn. Mater. 217, 35 (2000). http://dx.doi.org/10.1016/S0304-8853(00)00325-5

10. M. F. Yan and D. W. Johnson, J. Am. Ceram. Soc. 61, 342 (1978). http://dx.doi.org/10.1111/j.1151-2916.1978.tb09325.x

11. H. Igarashi and K. Okazaki, J. Am. Ceram. Soc. 60, 51 (1977). http://dx.doi.org/10.1111/j.1151-2916.1977.tb16092.x

12. W. D. Kingery and M. D. Narasimhan, J. Appl. Phys. 30, 307 (1959). http://dx.doi.org/10.1063/1.1735156

13. D. Vladikova and L. Ilkov, Phys. State Sol. A 111, 145 (1989). http://dx.doi.org/10.1002/pssa.2211110115

14. N. J. Shaw, Adv. Ceram. Powder Metall. International 21, 16 (1989).

15. A. Nakata, H. Chihara, and A. Sasaki, J. Appl. Phys. 57, 4177 (1985).

16. A. Rec`nik, M. C`eh, and D. Kolar, J. Eur. Ceram. Soc. 21, 2117 (2001). http://dx.doi.org/10.1016/S0955-2219(01)00184-4

17. A. H. Qureshi, J. Cryst. Growth 286, 365 (2006). http://dx.doi.org/10.1016/j.jcrysgro.2005.10.016

18. H. Shokrollahi and K. Janghorban, J. Magn. Magn. Mater. 308, 238 (2007). http://dx.doi.org/10.1016/j.jmmm.2006.05.023

19. C. S. Liu, IEEE Trans. Magn. 32, 4860 (1996). http://dx.doi.org/10.1109/20.539176

20. J. W. Cahn, Acta Metall. 10, 789 (1962). http://dx.doi.org/10.1016/0001-6160(62)90092-5

21. P. Andrei, O. F. Caltun, C. Papusoi, A. Stancu, and M. Feder, J. Magn. Magn. Mater. 196-197, 362 (1999). http://dx.doi.org/10.1016/S0304-8853(98)00750-1

22. H. Shokrollahi, K. Janghorban, Iran. J. Sci. Technol. Trans. B Eng. 30, 413 (2006).

23. I. N. Lin, R. K. Mishra, and G. Thomas, Trans. Magn. 22, 175 (1986). http://dx.doi.org/10.1109/TMAG.1986.1064289

24. N. Rezlescu, L. Rezlescu, P. D. Popa, and E. Rezlescu, J. Magn. Magn. Mater. 215-216, 194 (2000). http://dx.doi.org/10.1016/S0304-8853(00)00114-1

25. H. Shokrollahi, J. Magn. Magn. Mater. 320, 463 (2008). http://dx.doi.org/10.1016/j.jmmm.2007.07.003

26. P. A. Shaikh, R. C. Kambale, A. V. Rao, Y. D. Kolekar, J. Alloys Compd. 482, 276 (2009). http://dx.doi.org/10.1016/j.jallcom.2009.03.187

27. E. Calderón-Ortiz, O. Perales-Perez, P. Voyles, G. Gutierrez, and M. S. Tomar, Microelec. J. 40, 677 (2009). http://dx.doi.org/10.1016/j.mejo.2008.10.003

28. J. G. Hou, Y. F. Qu, W. B. Ma, and Q. C. Sun, J. Sol-Gel Sci. Technol. 44, 15 (2007). http://dx.doi.org/10.1007/s10971-007-1600-4

29. H. Su, H. W. Zhang, X. L. Tang, Y. L. Jing, Mater. Chem. Phys. 102, 271 (2007). http://dx.doi.org/10.1016/j.matchemphys.2007.01.004

30. O. Mirzaee, M. A. Golozar, A. Shafyei, Mater. Charact. 59, 638 (2008). http://dx.doi.org/10.1016/j.matchar.2007.05.016

31. J. Zhu, and K. J. Tseng, IEEE Trans Magn. 40, 3339 (2004). http://dx.doi.org/10.1109/TMAG.2004.833296

32. V. T. Zaspalis, E. Antoniadis, E. Papazoglou, V. Tsakaloudi, L. Nalbandian, and C. A. Sikalidis, J. Magn. Magn. Mater. 250, 98 (2002). http://dx.doi.org/10.1016/S0304-8853(02)00367-0

33. M. M. Rahaman, M. Phil. Thesis, Department of Physics (KUET), Bangladesh (2007).

34. B. D. Cullity, Introduction to Magnetic Materials (Addison-Wesley, California, 1972). 
35. A. Gonchar, J. Magn.Mag. Mater. 254-255, 544 (2003). http://dx.doi.org/10.1016/S0304-8853(02)00860-0

36. A. D. P. Rao, B. Ramesh, P. R. M. Rao, and S. B. Raju, J. Alloys Compd. 282, 268 (1999). http://dx.doi.org/10.1016/S0925-8388(98)00823-8

37. K. Wagner, Ann. Phys., 40, 817 (1913). http://dx.doi.org/10.1002/andp.19133450502

38. P. S. A. Kumar, J. J. Shrotri, C. E. Deshpande, and S. K. Date, J. Appl. Phys. 81, 4788 (1997). http://dx.doi.org/10.1063/1.365464

39. K. Sun, Z. W. Lan, Z. Yu, L. Z. Li, H. N. Ji, and Z. Y. Xu, Mater. Chem. Phys. 113, 797 (2009). http://dx.doi.org/10.1016/j.matchemphys.2008.08.052

40. Q. Xing, Z. Peng, C. Wang, Z. Fu, and X. Fu, Physica B 407, 388 (2012). http://dx.doi.org/10.1016/j.physb.2011.11.003

41. N. Debnath, M. S. Thesis, Department of Physics, Jahangirnagar University, Savar, Dhaka1342, Bangladesh (2010).

42. D. Jiles, Introduction to Magnetism and Magnetic Materials (London Chapman \& Hall CRC, 1998).

43. R. Valzuela, J. Mat. Sci. 15, 3137 (1980).

44. L. Hongying, Z. Haifeng, Y. Lanying, X. Jijing, G. Ssucai, M. Jian, and H. Guangyan, J. Rare Earth 25, 590 (2007).

45. S. R. Murthy, Bull. Mater. Sci. 24 (4), 379 (2001). http://dx.doi.org/10.1007/BF02708634

46. K. L. Kaiser, Electromagnetic Compatibility Hand Book (CRC Press, 2004).

47. M. A. Ahmed, N. Okasha, and M. M. El-Sayed, Ceram. Int. 33, 49 (2007). http://dx.doi.org/10.1016/j.ceramint.2005.07.014

48. A. D. P. Rao, P. R. M. Rao, and S. B. Raju, Mater. Chem. Phys. 65, 90 (2000). http://dx.doi.org/10.1016/S0254-0584(00)00220-0

49. M. Kaiser, J. Alloys Compd. 468, 15 (2009). http://dx.doi.org/10.1016/j.jallcom.2008.01.070

50. P. V. Dhanaraj and N. P. Rajesh, Physica B 406, 12 (2011). http://dx.doi.org/10.1016/j.physb.2010.09.041

51. C. Mu, N. Chen, X. Pan, X. Shen, X. Gu, Mater. Lett. 62, 840 (2008). http://dx.doi.org/10.1016/j.matlet.2007.06.074

52. Z. Haijun, L. Zhichao, M. Chenliang, Y. Xi, Z. Liangying, and W. Mingzhong, Mater. Chem. Phys. 80, 129 (2003). http://dx.doi.org/10.1016/S0254-0584(02)00457-1

53. B. K. Kuanr and G. P. Srivastava, J. Appl. Phys. 75, 6115 (1994). http://dx.doi.org/10.1063/1.355478

54. S. C. Watawe, B. D. Sarwade, S. S. Bellad, B. D. Sutar and B. K. Chougule, J. Magn. Magn. Mater. 214, 55 (2000). http://dx.doi.org/10.1016/S0304-8853(00)00033-0 